\title{
The Essential Oil from Angelica gigas NakaI Suppresses Nicotine Sensitization
}

\author{
Rong Jie ZhaO, ${ }^{a}$ Byung Soo Koo, ${ }^{b}$ Geun Woo KIm,${ }^{b}$ Eun Young JANG,${ }^{a}$ Jong Rok LeE, ${ }^{a}$ \\ Mi Ryeo KIm, ${ }^{a, c}$ Sang Chan KIm, ${ }^{a, c}$ Young Kyu Kwon, ${ }^{c}$ Kwang Joong KIM, ${ }^{c}$ Tae-lin HuH, ${ }^{d}$ \\ Dae-Hyun KIM, ${ }^{e}$ Insop SHIM, and Chae Ha Y ${ }_{\text {ANG }}{ }^{*, a, c}$ \\ ${ }^{a}$ The Research Center for Biomedical Resources of Oriental Medicine, Daegu Haany University; Daegu 706-828, Korea: \\ ${ }^{b}$ College of Oriental Medicine, Dongguk University; Gyeongju 780-714, Korea: ${ }^{c}$ College of Oriental Medicine, Daegu \\ Haany University; Daegu 706-628, Korea: ${ }^{d}$ TG Biotech Co. Ltd. Techno Building, Kyungpook National University; Daegu \\ 702-832, Korea: ${ }^{e}$ School of Medicine, Keimyung University; Daegu 700-712, Korea: and ${ }^{f}$ College of Medicine, The \\ Catholic University of Korea; Seoul 137-701, Korea. Received April 25, 2005; accepted July 19, 2005
}

Behavioral sensitization, as evidenced by the progressive enhanced locomotor response to a subsequent injection of the drug, is the major behavioral outcome produced by repeated injections of nicotine, and a model for studying drug addiction. It is putatively regarded that the alteration of extracellular dopamine release in the nucleus accumbens is closely associated with nicotine-induced behavioral sensitization. The present study was performed to evaluate the effects of the essential oil from Angelica gigas NAKAI (on fragrance inhalation) on repeated nicotine-induced locomotor activity and extracellular dopamine levels in the nucleus accumbens of rats using in vivo microdialysis. Rats were given repeated injections of saline or nicotine $(0.4 \mathrm{mg} / \mathrm{kg}$ s.c., twice a day for $7 \mathrm{~d})$, followed by one challenge injection on the 4th day after the last daily injection. Systemic challenge with nicotine $(0.4 \mathrm{mg} / \mathrm{kg} \mathrm{s.c.})$ produced a larger increase in locomotor activity in nicotine-pretreated rats than in saline-pretreated rats. A direct local challenge of $3 \mathrm{~mm}$ nicotine via a microdialysis probe also induced a larger increase in dopamine release in nicotine-pretreated rats than in saline-pretreated rats. Most importantly, our results showed that inhalation of the essential oils from Angelica gigas NAKAI significantly decreased both dopamine release in the nucleus accumbens and locomotor activity induced by a nicotine challenge. These results suggest that the essential oils from Angelica gigas NAKAI inhibit nicotine-induced behavioral and neurochemical sensitization, and imply that the essential oil from Angelica gigas NAKAI may be effective in treating nicotine addiction, possibly by modulating dopamine release in the nucleus accumbens.

Key words Angelica gigas; nicotine; dopamine; essential oil; locomotor activity; aromatherapy

Nicotine as an alkaloid agonist of nicotinic acetylcholine receptors (nAChRs) facilitates dopamine release through activating postsynaptic nAChRs located in dopamine neurons in the ventral tegmental area (VTA) and presynaptic nAChRs in the nucleus accumbens (NAc). ${ }^{1-3)}$ Repeated administration of all addictive drugs, including nicotine, can produce behavioral sensitization, as evidenced by an enhanced locomotor response to a subsequent injection of the drug. ${ }^{4-6)} \mathrm{Be}-$ havioral sensitization is thought to play a pivotal role in certain aspects of drug addiction, such as compulsive drug-seeking behavior. ${ }^{7)}$ The neurobiological substrate for behavioral sensitization of nicotine is believed to in some way involve the dopamine (DA) system of the NAc, a primitive structure that is implicated in positive reinforcing properties and the locomotor stimulation of drugs. ${ }^{8,9)}$

The dried radix of Angelica gigas NAKAI (AGN), termed "Korean Dang Gui", together with other medicinal herbs of Umbelliferae such as Angelica sinensis ("Chinese Dang Gui") and Angelica acutiloba ("Japanese Dang Gui"), has been traditionally used for the treatment of gynecological diseases such as menoxenia and anemia via its hemogenic, analgesic and sedative activities in Korean herbal prescriptions. $^{10-12)}$

Few experiments have investigated the effect of AGN on drug addiction; however, the results of some animal studies provided evidence for the involvement of the central nervous system in its effect. For example, a total methanolic extract of AGN significantly inhibited acetylcholinesterase (AchE) activity and mitigated the amnesia induced by scopolamine administration in mice. ${ }^{13,14)}$ Furthermore, inhalation of essential oil from Angelica sinensis exhibited anxiolytic-like effects in three murine tests of anxiety. ${ }^{15)}$ In addition, ligustilide and butylidenephthalide, the major components of the essential oil from Angelica acutiloba, have been shown to reverse the isolation stress-induced decrease in pentobarbital sleep in mice through central noradrenergic or $\mathrm{GABA}_{\mathrm{A}}$ receptors. $^{16)}$

It is well known that olfaction influences the behavior of mammals, and the olfactory system has a massive (direct or indirect) anatomical connection to the limbic system. ${ }^{17}$ For example, the inhalation of fragrance produces a variety of physiological effects, including brain, endocrine and immune functions. ${ }^{18-20)}$ Thus, it can be hypothesized that inhalation of an essential oil can be used as a therapeutic intervention for correcting a reversible malfunction of the body by direct activation of a targeted brain pathway. In the present study, we investigated the effects of inhalation of essential oil from AGN on chronic nicotine-induced DA release in the shell of NAc and behavioral sensitization in rats.

\section{MATERIALS AND METHODS}

Subjects Subjects were male Sprague-Dawley rats (Daehan Animal, Seoul, Korea), weighing between 280 and $300 \mathrm{~g}$ at the start of the experiment. All rats were kept on $\mathrm{ad}$ libitum food and water and maintained under standard conditions (room temperature: $21 \pm 2{ }^{\circ} \mathrm{C}$, relative humidity: $55-$ $65 \%$, light-dark cycle: $12 \mathrm{~h}$ ). All experimental procedures 
were carried out in accordance with the animal care guidelines of the National Institutes of Health (NIH).

Preparation of Essential Oil from Angelica gigas NAKAI (EOAGN) and Mentha arvensis L. var. piperascens MALINV. (EOMAP) Dried roots of Angelica gigas NAKAI $(300 \mathrm{~g})$ and the leaves and stems of Mentha arvensis L. var. piperascens MALINV. (MAP) (268 g) were purchased from a traditional herb market located in Daegu, Korea, and were identified by Prof. Sang Chan Kim, College of Oriental Medicine, Daegu Haany University, Daegu, Korea. A voucher specimen of this plant material is on deposit at the Herbarium (DGH-KSC2004) of this college. Dried roots of AGN, and the leaves and stems of MAP were pulverized and extracted once in 21 of $n$-hexane at room temperature for $48 \mathrm{~h}$, then filtered. The filtrate was evaporated at $50{ }^{\circ} \mathrm{C}$ to remove hexane. Hexane was further eliminated in a vacuum for $30 \mathrm{~min}$ at room temperature to give clear pale brown essential oils (EOAGN: $10.3 \mathrm{~g}$, EOMAP: $12.2 \mathrm{~g}$ ).

Determination of Extracellular DA A microdialysis guide cannula (CMA11, Carnegie Medicin, Stockholm, Sweden) was stereotaxically implanted in rats under anesthesia using coordinates for the NAc shell region (AP 1.7, ML 0.8, DV -6.0), according to the atlas of Paxinos and Watson. ${ }^{21)}$ Immediately after microdialysis probes (CMA11, Cuprophane dialysis membrane, $6000 \mathrm{Da}, 2 \mathrm{~mm}$ length) were inserted through the guide cannula into the brain of anaesthetized rats, the microdialysis fluid was perfused at a rate of $1.5 \mu \mathrm{l} / \mathrm{min}$ (CMA100 Microinjection pump). The microdialysis fluid was a modified Ringer's solution containing $150 \mathrm{~mm}$ $\mathrm{NaCl}, 3.0 \mathrm{~mm} \mathrm{KCl}, 1.4 \mathrm{mM} \mathrm{CaCl}_{2}$, and $0.8 \mathrm{mM} \mathrm{MgCl}_{2}$ in $10 \mathrm{~mm}$ phosphate buffer at $\mathrm{pH}$ 7.1. Before use in vivo, microdialysis probes were calibrated in vitro by dialysis against a solution of DA prepared in a modified Ringer's buffer to determine its recovery value. Probe recovery values were used to normalize microdialysate DA concentrations, and all reported results are based on levels corrected for individual probe recovery.

Two hours after microdialysis perfusion, dialysates were collected at $20 \mathrm{~min}$ intervals through a $40 \mathrm{~cm}$ tube (i.d., $0.12 \mathrm{~mm}$ ) until a stable baseline of DA was obtained. Baseline DA levels were defined as the means of three consecutive DA concentrations of dialysate exhibiting less than $\pm 10 \%$ variation. Following the establishment of baseline DA levels, animals were given a local perfusion of nicotine, and collection of microdialysis samples continued at $20 \mathrm{~min}$ intervals for $120 \mathrm{~min}$. The DA concentration in the samples was assayed using HPLC equipped with a coulometric detector (Coulochem II, ESA, Bedford, MA, U.S.A.). The mobile phase was composed of $75 \mathrm{~mm}$ sodium phosphate monobasic, $1.7 \mathrm{~mm}$ sodium octane sulfonate, $25 \mu \mathrm{M}$ EDTA, $0.714 \mathrm{~mm}$ triethylamine, and $10 \%$ acetonitrile with the $\mathrm{pH}$ adjusted to 3.0. The mobile phase was pumped at a flow rate of $1.0 \mathrm{ml} / \mathrm{min}$. Separation of DA was performed on a HR-80 C18 column $(80 \times 4.6 \mathrm{~mm}, 3 \mu \mathrm{m}, \mathrm{ESA})$. The detector was equipped with a high performance analytical cell (model 5014B, ESA). The first potential was set at $-100 \mathrm{mV}$, and the second was at $+350 \mathrm{mV}$. A guard cell was set at $+400 \mathrm{mV}$. DA content in the dialysate was expressed as a percentage of baseline DA levels. At the end of the dialysis experiments, probe placements were confirmed with histological $100 \mu \mathrm{m}$ coronal brain sections stained with cresyl violet. Animals were ex- cluded from the statistical analysis if histological examination revealed that the microdialysis probe was not located in the NAc shell.

Measurement of Locomotor Activity Rats were housed individually prior to behavioral testing. Locomotor activity was measured in a rectangular container $(40 \times 40 \times 45 \mathrm{~cm})$ equipped with a video camera above the center of the floor. The walls and floor were made of a clear plexiglas and were painted black. The locomotor activity was monitored by a videotracking system using the Ethovision program (Noldus Information Technology BV, Wageningen, Netherlands). Animals were allowed to adapted for $1 \mathrm{~h}$ in the box, and the distance traveled was recorded during $1 \mathrm{~h}$ baseline and $1 \mathrm{~h}$ treatment.

Experimental Procedure The first experiment was undertaken to study the effect of EOAGN on changes in extracellular DA levels in the NAc induced by repeated injections of (-)-nicotine hydrogen tartrate (Sigma, St. Louis, MO, U.S.A.). Rats were treated repeatedly with nicotine $(0.4$ $\mathrm{mg} / \mathrm{kg}$, s.c., free base dissolved in saline at $\mathrm{pH}$ 7.2) or saline twice a day for $7 \mathrm{~d}$, followed by a direct local injection of $3 \mathrm{~mm}$ nicotine on the 4th day after the last daily injection. For the local challenge, nicotine dissolved in microdialysis fluid at $\mathrm{pH} 7.2$ was infused locally through a dialysis probe inserted into the NAc for $20 \mathrm{~min}$. In the N/A/N group, rats inhaled EOAGN before the nicotine challenge. In the N/M/N group, EOMAP was treated as a control essential oil. Nicotine-pretreated rats $(\mathrm{N} / \mathrm{S} / \mathrm{N}$ group) or saline-pretreated rats ( $\mathrm{S} / \mathrm{S} / \mathrm{N}$ group) were treated with a local perfusion of nicotine alone in the absence of essential oil inhalation. In order to investigate the effect of EOAGN alone on DA release, DA was determined before and after exposure to EOAGN in the saline-pretreated rats (S/A/S group). For comparative purposes, the $\mathrm{S} / \mathrm{S} / \mathrm{S}$ group was also included.

The second experiment was designed to investigate the effect of EOAGN on behavioral sensitization using the same nicotine pretreatment design. Locomotor activity was measured using different rats after a systemic challenge with nicotine $(0.4 \mathrm{mg} / \mathrm{kg}$, s.c. $)$.

Inhalation of the essential oil was carried out in a special cage (Three-Shine Co., Seoul, Korea) for $24 \mathrm{~h}$ before the start of the microdialysis session. Two grams of essential oil was put in each cage $(\mathrm{W} 26 \times \mathrm{L} 22 \times \mathrm{H} 20 \mathrm{~cm})$ for evaporation (when sham inhalation was carried out, saline was substituted for EOAGN). The cage was capped with a special filter, which allowed minimum breathing air to pass.

Statistical Analysis Statistical analysis of data was carried out using the SPSS 8.0 and Statview 5.0 software programs. Neurochemical data were analyzed using repeated measures ANOVA, and behavioral data were analyzed by one-way ANOVA. All post hoc comparisons were further examined by the Tukey technique.

\section{RESULTS AND DISCUSSION}

Basal DA levels in the NAc of each group were as follows: $5.75 \pm 0.93 \mathrm{nM}$ for the $\mathrm{N} / \mathrm{S} / \mathrm{N}$ group, $4.96 \pm 0.96 \mathrm{~nm}$ for the $\mathrm{N} / \mathrm{A} / \mathrm{N}$ group, $7.31 \pm 0.83 \mathrm{~nm}$ for the $\mathrm{N} / \mathrm{M} / \mathrm{N}$ group, $6.25 \pm$ $1.13 \mathrm{~nm}$ for the $\mathrm{S} / \mathrm{S} / \mathrm{N}$ group, $5.74 \pm 0.44 \mathrm{~nm}$ for the $\mathrm{S} / \mathrm{A} / \mathrm{S}$ group, and $6.32 \pm 0.81 \mathrm{~nm}$ for the $\mathrm{S} / \mathrm{S} / \mathrm{S}$ group, respectively. These results parallel others which demonstrated a similar 
basal DA concentration in the NAc. ${ }^{22)}$ Extracellular DA concentration in the $\mathrm{S} / \mathrm{S} / \mathrm{N}$ group was increased by $246.6 \pm$ $51.8 \%$ and $401.7 \pm 59.7 \%$, relative to baseline, at $20 \mathrm{~min}$ and $40 \mathrm{~min}$ after local perfusion of nicotine directly into the NAc, respectively, while extracellular DA concentration in the $\mathrm{N} / \mathrm{S} / \mathrm{N}$ group was increased by $643.3 \pm 46.1 \%$ and $881.7 \pm$ $83.0 \%$, relative to baseline, at $20 \mathrm{~min}$ and $40 \mathrm{~min}$ after local perfusion of nicotine directly into the NAc, respectively. Inhalation of EOAGN, but not EOMAP, significantly inhibited the increase of extracellular DA concentration in the NAc induced by a local challenge with nicotine in nicotine-pretreated rats. The $\mathrm{N} / \mathrm{A} / \mathrm{N}$ group reduced increases in $\mathrm{DA}$ release in the $\mathrm{N} / \mathrm{S} / \mathrm{N}$ group by $65.2 \%$ and $71.1 \%$ at $20 \mathrm{~min}$ and $40 \mathrm{~min}$ after a local nicotine challenge, respectively (Fig. 1).

On the 4th day after the last daily injection of nicotine, a systemic challenge with nicotine produced a much larger increase in locomotor activity in nicotine-pretreated rat compared to saline-pretreated rat. Horizontal locomotor activity measured by distance during the $60 \mathrm{~min}$ testing period after nicotine challenge was $4399 \pm 414 \mathrm{~cm}$ in the $\mathrm{N} / \mathrm{S} / \mathrm{N}$ group, $2630 \pm 384 \mathrm{~cm}$ in the N/A/N group, $4887 \pm 557 \mathrm{~cm}$ in the $\mathrm{N} / \mathrm{M} / \mathrm{N}$ group, $1922 \pm 209 \mathrm{~cm}$ in the $\mathrm{S} / \mathrm{S} / \mathrm{N}$ group, $1681 \pm 222$ $\mathrm{cm}$ in the $\mathrm{S} / \mathrm{A} / \mathrm{S}$ group, and $1595 \pm 223 \mathrm{~cm}$ in $\mathrm{S} / \mathrm{S} / \mathrm{S}$ group, respectively. Similar to the DA data, inhalation of EOAGN, but not EOMAP significantly reduced the amount of nicotine-induced hyperactivity (Fig. 2). However, neither DA release in the NAc or locomotor activity were affected by EOAGN in the vehicle (saline)-treated group.

These results showed that the nicotine challenge produced a much larger increase in DA release and locomotor activity in nicotine-pretreated rats compared to saline-pretreated rats. These results are consistent with the other studies indicating that repeated nicotine administration produces sensitization of extracellular DA levels in the NAc and behavioral sensitization in rats, as evidenced by an enhanced locomotor response and DA release in brain. ${ }^{9,23,24)}$ Some studies have provided evidence that nicotine-induced enhancement of DA transmission in the NAc is linked to the reinforcing effect of nicotine, and may be implicated in the development of behavioral sensitization. ${ }^{9)}$ Thus, nicotine-induced elevations of DA in the NAc may play a key role in the development and maintenance of nicotine-seeking behavior. Most importantly, our results showed that the inhalation of EOAGN, but not control or inhalation of EOMAP, significantly decreased both DA release in the nucleus accumbens and locomotor activity induced by the nicotine challenge. These results suggest that the reduced hyperlocomotor activity produced by EOAGN is most likely mediated via an inhibition of the mesolimbic DA system, as revealed by the parallel decrease of DA release in the NAc. Although few experiments have investigated the effect of EOAGN on drugs of abuse, including nicotine, it has recently been shown that a methanolic extract of AGN suppresses AchE activity, and that coumarin derivatives from an extract of AGN produces anti-amnesic activity in behavioral tests through the inhibition of AchE activity in the hippocampus. $^{13,15)}$ Importantly, considerable studies have provided strong evidence that AchE inhibitors prevent, to a great extent, behavioral sensitization and the rewarding effects of cocaine and morphine, and that cholinergic cell ablation enhances the long-lasting behavioral changes of cocaine addiction. $^{25,26)}$ These results indicate that acetylcholine increases

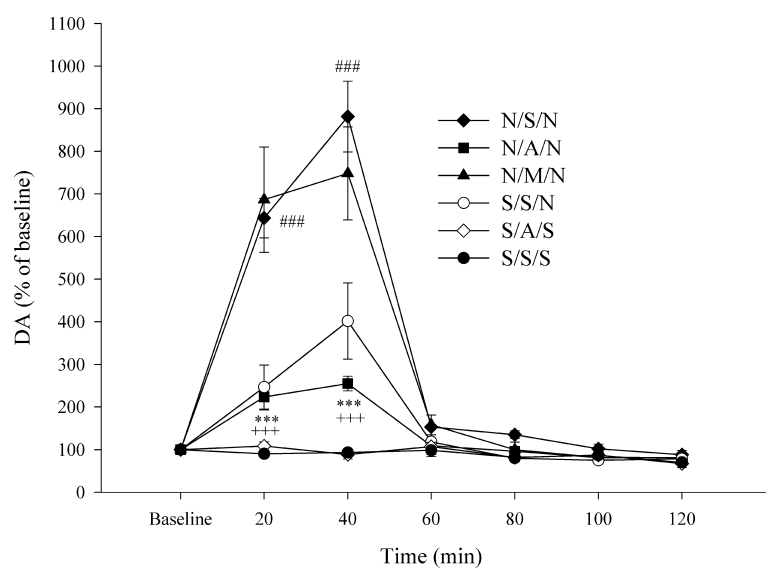

Fig. 1. Effects of Inhalation of EOAGN on Extracellular DA Levels in the NAc of Male Sprague-Dawley Rats Treated Repeatedly with $0.4 \mathrm{mg} / \mathrm{kg} / \mathrm{d}$ of Nicotine or Saline by Subcutaneous Injection Twice Daily for $7 \mathrm{~d}$ Followed by a Local Perfusion of Nicotine ( $3 \mathrm{~mm}$ ) $4 \mathrm{~d}$ after the Last Daily Injection

Results are mean \pm S.E.M. of the amount of dopamine in each sample expressed as percent of basal values. N/S/N group, $n=6 ; \mathrm{N} / \mathrm{A} / \mathrm{N}$ group, $n=8 ; \mathrm{N} / \mathrm{M} / \mathrm{N}$ group, $n=6$; $\mathrm{S} / \mathrm{S} / \mathrm{N}$ group, $n=6 ; \mathrm{S} / \mathrm{A} / \mathrm{S}$ group, $n=6 ; \mathrm{S} / \mathrm{S} / \mathrm{S}$ group, $n=6$; repeated ANOVA and post hoc Tukey test. $* * * p<0.001, \mathrm{~N} / \mathrm{A} / \mathrm{N}$ group $v s . \mathrm{N} / \mathrm{S} / \mathrm{N}$ group; \# $p<0.001, \mathrm{~N} / \mathrm{S} / \mathrm{N}$ group vs. $\mathrm{S} / \mathrm{S} / \mathrm{N}$ group; ${ }^{+++} p<0.001, \mathrm{~N} / \mathrm{A} / \mathrm{N}$ group $v s . \mathrm{N} / \mathrm{M} / \mathrm{N}$ group.

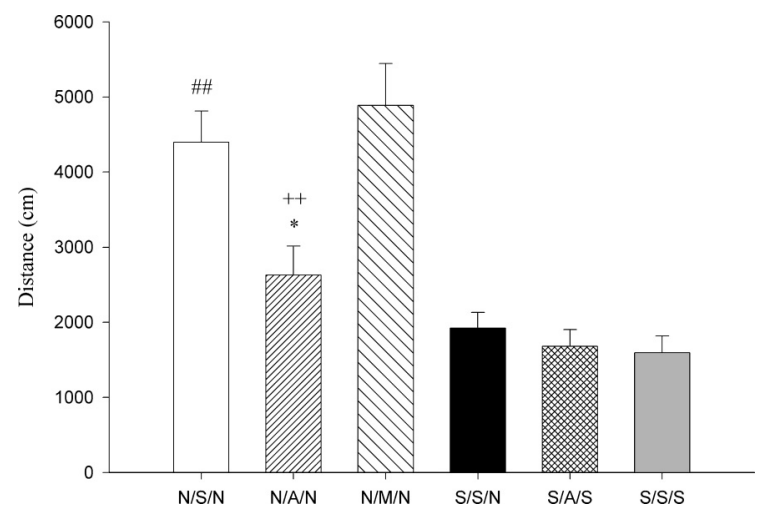

Fig. 2. Effects of Inhalation of EOAGN on Locomotor Responses in Sparague-Dawley Rats Treated Repeatedly with $0.4 \mathrm{mg} / \mathrm{kg} / \mathrm{d}$ of Nicotine or Saline by Subcutaneous Injection Twice Daily for $7 \mathrm{~d}$ Followed by a Single Subcutaneous Injection of Nicotine $(0.4 \mathrm{mg} / \mathrm{kg}) 4 \mathrm{~d}$ after the Last Daily Injection

Results are shown as means \pm S.E.M. N/S/N group, $n=6 ; \mathrm{N} / \mathrm{A} / \mathrm{N}$ group, $n=6 ; \mathrm{N} / \mathrm{M} / \mathrm{N}$ group, $n=6 ; \mathrm{S} / \mathrm{S} / \mathrm{N}$ group, $n=6 ; \mathrm{S} / \mathrm{A} / \mathrm{S}$ group, $n=6 ; \mathrm{S} / \mathrm{S} / \mathrm{S}$ group, $n=6$; one-way ANOVA and post hoc Tukey test. $* p<0.05$, N/A/N group $v s$. N/S/N group; $p<0.01$, $\mathrm{N} / \mathrm{S} / \mathrm{N}$ group $v s . \mathrm{S} / \mathrm{S} / \mathrm{N}$ group; ${ }^{++} p<0.05, \mathrm{~N} / \mathrm{A} / \mathrm{N}$ group $v s . \mathrm{N} / \mathrm{M} / \mathrm{N}$ group.

in the NAc may play a significant modulatory role in DA action involved in drug reinforcement and addiction. Furthermore, ligustilide and butylidenephthalide, the major components of angelica essential oil, could reverse the isolation stress-induced decrease in pentobarbital sleep in mice through central $\mathrm{GABA}_{\mathrm{A}}$ receptors. ${ }^{16)}$ GABAergic neurons are known to dampen DA neurons via inhibitory $\mathrm{GABA}_{\mathrm{A}}$ receptors in the mesolimbic DA system. ${ }^{27)}$ Recently it has been shown that the $\mathrm{GABA}_{\mathrm{A}}$ receptor agonist significantly attenuated both the dopaminergic and behavioral response to cocaine challenge. ${ }^{28)}$ Thus, it is likely that this inhibitory control may attenuate the rewarding and reinforcing effect of drugs of abuse. Based on these results and the notion that nicotine has a common neurochemical and behavioral properties common to other psychostimulants such as cocaine and amphetamine, ${ }^{29)}$ we expect that Ach enhancement and 
$\mathrm{GABA}_{\mathrm{A}}$ receptors are involved in the EOAGN's action. Elucidation of the specific mechanisms involved in EOAGN-induced reduction of nicotine sensitization will require additional study.

Recently, aromatic therapy has attracted researchers' attention since it shows benefits of improving depressed moods and in treating mental disorders. It is well documented that many commercial odors and fragrances of essential oils from plants have effects on the central nervous system. Anatomically, the olfactory system has massive (direct or indirect) connection to a variety of central nervous system component, including the hypothalamus, hippocampus and limbic system. ${ }^{30,31)}$ Therefore, it is highly likely that EOAGN may have the ability to correct brain function by direct activation of the brain pathway, and thus contribute to biochemical balance in the central nervous system.

In conclusion, our results provide strong evidence that the inhalation of EOAGN attenuates the sensitization of extracellular dopamine levels in the NAc and behavioral sensitization induced by repeated nicotine treatment. These results suggest that EOAGN may be effective in treating nicotine addiction, possibly by modulating DA release in the nucleus accumbens.

Acknowledgement This work was supported by a grant (R12-2003-002-03001-0) from the basic research program of the Ministry of Commerce, Industry and Energy, Korea.

\section{REFERENCES}

1) Clarke P. B., Pert A., Brain Res., 348, 355-358 (1985).

2) De Belleroche J., Lugamini Y., Bradeford H. F., Neurosci. Lett., 11, 209-213 (1979).

3) Brazel M. P., Mitchel S. N., Joseph M. H., Gray J. A., Neuropharmacology, 29, 1177-1185 (1990).

4) Robinson T. E., Becker J. B., Brain Res. Rev., 11, 157-198 (1986).

5) Heidbreder C. A., Babovic-Vuksanovic D., Shoaib M., Shippenberg T. S., J. Pharmacol. Exp. Ther., 275, 150-163 (1995).
6) Sills T. L., Fletcher P. J., Eur. J. Pharmacol., 337, 161-164 (1997)

7) Robinson T. E., Berridge K. C., Addiction, 96, 103-114 (2001).

8) Pierce R. C., Kalivas P. W., J. Pharmacol. Exp. Ther, 275, 10191029 (1995).

9) Shim I., Javaid J. I., Wirtshafter D., Jang S. Y., Shin K. H., Lee H. J., Behav. Brain Res., 121, 137-147 (2001).

10) Han D. S., "Pharmacognosy," 4th ed., Dongmyungsa Press, Seoul, 1992.

11) Lu X. H., Liang H., Zhao Y. Y., Zhongguo Zhong Yao Za Zhi, 28, $423-425$ (2003)

12) Yamada H., Kiyohara H., Cyong J. C., Otsuka Y., Mol. Immunol., 22, 295-304 (1985).

13) Kang S. Y., Lee K. Y., Sung S. H., Park M. J., Kim Y. C., J. Nat. Prod., 64, 683-685 (2001).

14) Kang S. Y., Lee K. Y., Park M. J., Kim Y. C., Markelonis G. J., Oh T. H., Kim Y. C., Neurobiol. Learn Mem., 79, 11-18 (2003).

15) Chen S. W., Min L., Li W. J., Kong W. X., Li J. F., Zhang Y. J., Pharmacol. Biochem. Behav., 79, 377-382 (2004).

16) Matsumoto K., Kohno S., Ojima K., Teziuka Y., Kadota S., Watanabe H., Life Sci., 62, 2073-2082 (1998).

17) Broughan C., Int. J. Aromatherapy, 12, $92-98$ (2002).

18) Tyler S. L., Int. J. Psychophysiol., 36, 91-104 (2000).

19) Komori T., Fujiwara R., Tanida M., Nomura J., Yokoyama M. M., Neuroimmunomodulation, 2, 174-180 (1995).

20) Haze S., Sakai K., Gozu Y., Jpn. J. Pharmacol., 90, 247-253 (2002).

21) Paxinos G., Watson C., "The Rat Brain in Stereotaxic Coordinates," Acadenmic Press, New York, 1986.

22) Di Chiara G., Imperato A., Eur. J. Pharmacol., 115, 131-132 (1985).

23) Lecca D., Shim I., Costa E., Javaid J., Neuropharmacology, 39, 8898 (2000).

24) Imperato A., Mulas A., Chiara Di G., Eur. J. Pharmacol., 132, 337338 (1986).

25) Hikida T., Kitabatake Y., Pastan I., Nakanishi S., Proc. Natl. Acad. Sci., U.S.A., 100, 6169-6173 (2003).

26) Hikida T., Kaneco S., Isobe T., Kitabatake Y., Watanabe D., Pastan I., Nakanish S., Proc. Natl. Acad. Sci., U.S.A., 98, 13351-13354 (2001).

27) Rahman S., McBride W. J., J. Neurochem., 80, 646-654 (2002).

28) Giorgetti M., Javaid J. I., Davis J. M., Costa E., Guidotti A., Appel S. B., Brodie M. S., J. Pharmacol. Exp. Ther, 287, 58-66 (1998).

29) Pontieri F. E., Tanda G., Orzi F., Di Chiara G., Nature (London), 382, 255-258 (1996).

30) Weier K. M., Beal M. W., J. Midwifery Womens Health, 49, 96-104 (2004).

31) Edge J., Complement Ther. Nurs. Midwifery, 9, 90—97 (2003). 